Check for updates

Cite this: RSC Adv., 2018, 8, 32003

Received 23rd August 2018

Accepted 10th September 2018

DOI: $10.1039 / \mathrm{c} 8 \mathrm{ra07068g}$

rsc.li/rsc-advances

\section{Discovering a new $\mathrm{MgH}_{2}$ metastable phase $\dagger$}

\author{
Mohamed Sherif El-Eskandarany, (D) * Mohammad Banyan and Fahad Al-Ajmi
}

Formation of a new metastable $\mathrm{fcc}-\mathrm{MgH}_{2}$ nanocrystalline phase upon mechanically-induced plastic deformation of $\mathrm{MgH}_{2}$ powders is reported. Our results have shown that cold rolling of mechanically reacted $\mathrm{MgH}_{2}$ powders for 200 passes introduced severe plastic deformation of the powders and led to formation of micro-lathes consisting of $\gamma$ - and $\beta-\mathrm{MgH}_{2}$ phases. The cold rolled powders were subjected to different types of defects, exemplified by dislocations, stacking faults, and twinning upon high-energy ball milling. Long term ball milling (50 hours) destabilized $\beta-\mathrm{MgH}_{2}$ (the most stable phase) and $\gamma-\mathrm{MgH}_{2}$ (the metastable phase), leading to the formation of a new phase of face centered cubic structure (fcc). The lattice parameter of fcc- $\mathrm{MgH}_{2}$ phase was calculated and found to be $0.4436 \mathrm{~nm}$. This discovered phase possessed high hydrogen storage capacity (6.6 wt\%) and revealed excellent desorption kinetics (7 min) at $275{ }^{\circ} \mathrm{C}$. We also demonstrated a cyclic-phase-transformation conducted between these three phases upon changing the ball milling time to 200 hours.
The worldwide interest in $\mathrm{MgH}_{2}$ is attributed to the natural abundance of $\mathrm{Mg}$ metal, and its capability to store hydrogen up to $7.60 \mathrm{wt} \%\left(0.11 \mathrm{~kg} \mathrm{H}_{2} \mathrm{~L}^{-1}\right) \cdot{ }^{1-3}$ Among the metal hydride family, $\mathrm{MgH}_{2}$ has been considered as a promising candidate for solidstate hydrogen storage. ${ }^{4-6}$ Despite the attractive properties of $\mathrm{MgH}_{2}$, and the simplicity for producing the compound on an industrial scale at ambient temperature via a reactive ball milling (RBM) technique, ${ }^{7,8} \mathrm{MgH}_{2}$ is a very stable compound, and possesses slow kinetics of hydrogenation and dehydrogenation under $300{ }^{\circ} \mathrm{C} .{ }^{9}$ Since the 1990 s efforts have been made in order to destabilize $\mathrm{MgH}_{2}$ and improve its hydrogenation and dehydrogenation kinetics upon doping with a long list of catalysts. ${ }^{10-15}$ Most of the used catalysts showed significant enhancement of the kinetics behavior for $\mathrm{MgH}_{2}$, indexed by a decreasing decomposition temperature and a speed-up of its kinetics behavior. ${ }^{16-20}$ In spite of the beneficial effects obtained upon adding such foreign catalytic agents, they always lead to a dramatic decrease of the hydrogen storage capacity of $\mathrm{MgH}_{2} \cdot{ }^{21,22}$

Apart from doping $\mathrm{MgH}_{2}$ powders with catalysts, it has been experimentally demonstrated by some authors that changing the crystal structure of stable $\beta$-tetragonal $\mathrm{MgH}_{2}$ phase to a less stable phase of $\gamma$-orthorhombic $\mathrm{MgH}_{2}$ led to improve the gas uptake/release kinetics and decrease the hydrogenation temperature without drastic decreasing of the storage capacity. ${ }^{23-26}$ The $\beta$-to- $\gamma$ phase transformations can be attained via severe plastic deformation (SPD) ${ }^{27}$ at ambient temperature

Nanotechnology and Advanced Materials Program, Energy and Building Research Center, Kuwait Institute for Scientific Research, Safat 13109, Kuwait. E-mail: msherif@kisr.edu.kw

$\dagger$ Electronic supplementary information (ESI) available. See DOI: 10.1039/c8ra07068g by different approaches such as high-energy ball milling (HEBM), ${ }^{28}$ cold rolling (CRing), ${ }^{29}$ equal channel angular pressing (ECAP), ${ }^{30}$ and high pressure torsion (HPT). ${ }^{22,31} \mathrm{~A}$ common result of these employed techniques is the formation of nanocrystalline phase along with introducing high intensity defects, leading to increase of grain boundaries density. Presence of these defects in the lattice leads to create nucleation points for hydrogenation, where existence of large number of grain boundaries assists fast diffusion pathways for hydrogen.

The present work has been addressed in part to study the effect of HEBM on the structure and decomposition properties of $\mathrm{CRed} \mathrm{MgH}_{2}$ powders. Moreover, we aimed to investigate experimentally the possibility of formation a new metastable $\mathrm{MgH}_{2}$ phase rather than the reported g-phase and theoretically calculated $\delta$ and $\varepsilon$ phases ${ }^{32}$ upon long term of milling.

For the purpose of the present study, $5 \mathrm{~g} \mathrm{Mg}(\sim 80 \mu \mathrm{m}$, $99.8 \mathrm{wt} \%$ ) powder was balanced inside a He gas atmosphereglove box and sealed together with fifty hardened steel-balls (11 $\mathrm{mm}$ in diameter), using ball-to-powder weight ratio as $40: 1$. The vial was then evacuated to the level of $10^{-3}$ bar and then filled with 50 bar of $\mathrm{H}_{2}$. The RBM process was carried out at room temperature, using planetary-type HEBM. After 25 hours (h) of RBM, the vial was open inside the glove box to discharge the powders. The powders were charged and sealed in a stainless steel (SUS304) tube ( $0.8 \mathrm{~cm}$ diameter and $20 \mathrm{~cm}$ length) inside the glove box. The tube contained $\mathrm{MgH}_{2}$ powders were severely CRed for different number of passes ( 1 to 200 passes), using two-drum type manual cold roller $(11 \mathrm{~cm}$ wide $\times 5.5 \mathrm{~cm}$ rollers diameter). The as-CRed powders for 200 passes were then HEBMed under hydrogen gas for different milling time, in the range between $3 \mathrm{~h}$ to $50 \mathrm{~h}$. All the samples were characterized by means of X-ray diffraction (XRD) with $\mathrm{Cu}$ radiation, 
field-emission high-resolution transmission electron microscope (FE-HRTEM) equipped with energy-dispersive X-ray spectroscopy (EDS), field emission scanning electron microscope (FE-SEM)/EDS, and differential scanning calorimeter (DSC). The absorption/desorption kinetics were investigated via Sievert's method in different temperatures under hydrogen gas pressure in the range between 200 mbar to 8 bar.

The XRD patterns of $\mathrm{MgH}_{2}$ powders obtained after $25 \mathrm{~h}$ of RBM is shown in Fig. 1a. Bragg peaks corresponding to starting hcp-Mg powders were hardly seen and replaced by sharp diffracted lines related to $\gamma$ - and $\beta-\mathrm{MgH}_{2}$ phases, as elucidated in Fig. 1a. The SEM observations indicated the powders tendency to agglomerate, forming large aggregates upon CRing for 25 passes (Fig. 2a). Increasing the CRing passes to 200 times led to grain refinement, as implied by the broadening in the Braggpeaks presented in Fig. 1b. At this stage, micro-bands with thickness of $143 \mu \mathrm{m}$ were developed as a result of cold working generated during CRing process, as shown in Fig. 2b. The FEHRTEM image of as-CRed powders for 200 passes indicated the development of lattice imperfections (e.g. stacking faults and deformation twins). This is implying the mechanicallyinduced SPD, as elucidated in ESI, Fig. S1. $\dagger$

In order to study the effect of HEBM on the stability of coldrolled $\mathrm{MgH}_{2}$ aggregates, the powders were charged into tool steel vial and ball milled under 50 bar of $\mathrm{H}_{2}$ for different milling time. The XRD pattern of CRed $\mathrm{MgH}_{2}$ powders obtained after $200 \mathrm{CR}$ passes and then HEBMed for $50 \mathrm{~h}$ is displayed in Fig. 1c. Obviously, the Bragg peaks corresponding to $\gamma$ - and $\beta-\mathrm{MgH}_{2}$ phases were completely vanished and replaced by new Bragg peaks of unreported phase, appeared at scattering angles $(2 \theta)$ of, 35.034, 40.584, 58.758, 70.115, and 73.868 (Fig. 1c). XRD analysis indicated that this discovered $\mathrm{MgH}_{2}$ phase has face centered cubic structure (fcc) of space group, $F m \overline{3} m(225)$. The lattice parameter $\left(a_{\mathrm{o}}\right)$ of this phase, calculated from (111) was
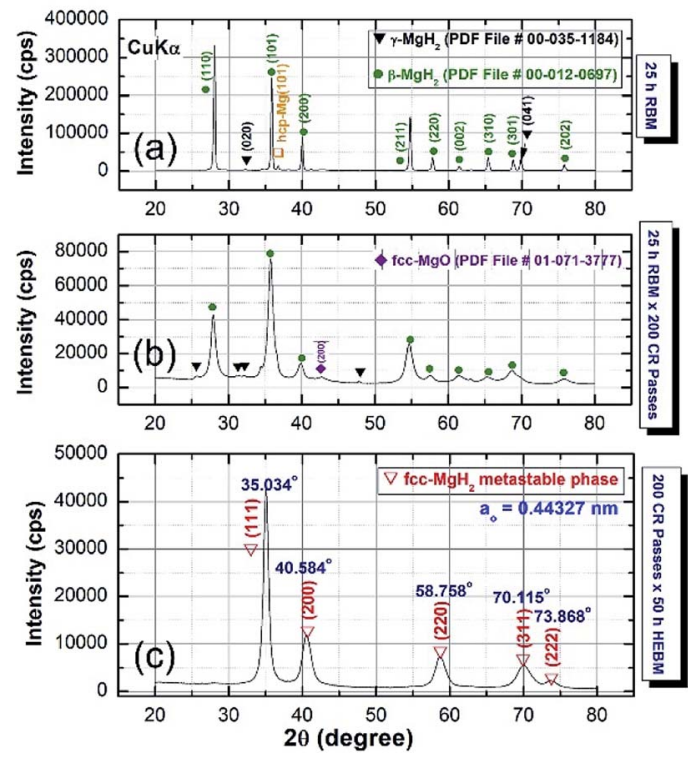

Fig. 1 XRD patterns of $\mathrm{MgH}_{2}$ powders obtained after $25 \mathrm{~h}$ of RBMing (a), and then CRed for 200 passes (b). XRD pattern of CRed powders for 200 passes and then HEBMEd for $50 \mathrm{~h}$ is presented in (c).

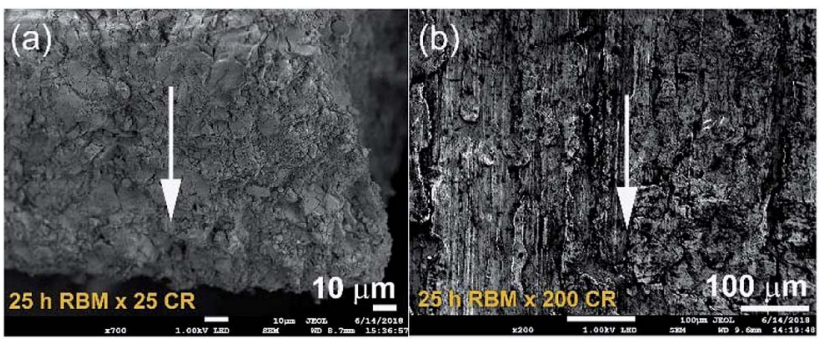

Fig. 2 FE-SEM micrographs taken at accelerated voltage of $1 \mathrm{kV}$ of $\mathrm{MgH}_{2}$ powders obtained after $25 \mathrm{~h}$ of RBMing and then CRed for (a) 25 , and (b) 200 passes.

$0.44361 \mathrm{~nm}$. The as-synthesized fcc- $\mathrm{MgH}_{2}$ powders had fine spherical particles with sizes distributed in the range between $0.25 \mu \mathrm{m}$ to $1 \mu \mathrm{m}$, as displayed in Fig. 3 .

Table 1 presents some of structural parameters related to this new phase, indexed by the interplanar spacing for the corresponding Miller indexes $(h, k, l)$ and $2 \theta$.

The FE-HRTEM image of the as-CRed powders for 200 passes and then HEBMed for $50 \mathrm{~h}$ is shown in Fig. 4. The image revealed Moiré fringe image for 3 intimated nanograins. Filtered-fringe images corresponding to Zone I is presented in Fig. 4a. The $d$-spacing related to fcc- $\mathrm{MgH}_{2}$ (111) was calculated and found to be $0.2559 \mathrm{~nm}$, where the corresponding $a_{\mathrm{o}}$ was calculated and found to be $0.4433 \mathrm{~nm}$. These values matches well with the XRD analysis (Table 1). The FFT image, which is displayed in Fig. 4c, was taken from Zone I and oriented to [001] axis, where the corresponding FFT showed spot-electron diffraction pattern related to fcc- $\mathrm{MgH}_{2}$ (111).

Fig. 5 presents DSC thermograms of $\mathrm{MgH}_{2}$ powders obtained after $25 \mathrm{~h}$ of RBM, consequently cold-rolled for 200 passes and then HEBM for different times, as indexed in Fig. 5. The DSC curves for the powders obtained after $25 \mathrm{~h}$ of RBM and then cold-rolled only without milling for different passes are shown together in ESI (Fig. S2†).

The decomposition temperature of the powders obtained after $25 \mathrm{~h}$ of RBM (before applying CRing process) was $415^{\circ} \mathrm{C}$ (Fig. S2 $\dagger$ ), and tended to decrease sharply to $361^{\circ} \mathrm{C}$ upon powders CRing for 200 passes, as displayed in Fig. S2. $\dagger$ This significant decreasing on the decomposition temperature upon increasing the number of

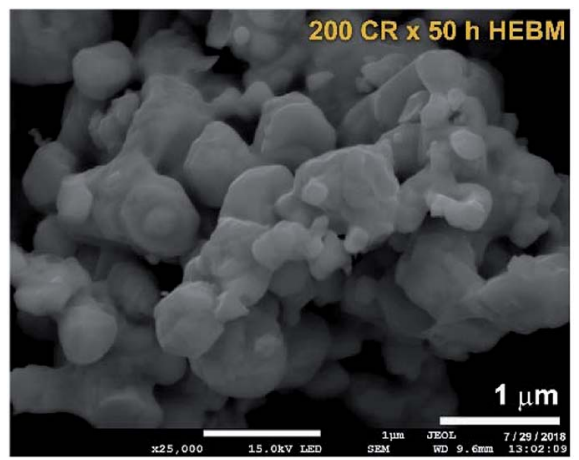

Fig. 3 FE-SEM micrograph of $\mathrm{MgH}_{2}$ powders obtained after $25 \mathrm{~h}$ of RBM, CRed for 200 passes and finally HEBMed for $50 \mathrm{~h}$. 
Table 1 Unit cell characteristics of discovered fcc- $\mathrm{MgH}_{2}$ phase prepared in the present work. The lattice parameter for each Miller indexes was calculated based on Bragg equation, using X-ray wavelength $(\lambda)$ of Cu radiation $(0.15418 \mathrm{~nm})$

\begin{tabular}{llll}
\hline Peak position, $2 \theta$ (degree) & Interplanar spacing, $d(\mathrm{~nm})$ & Miller indexes $(h, k, l)$ & Lattice parameter, $a_{\mathrm{o}}(\mathrm{nm})$ \\
\hline 35.034 & 0.25612 & 111 & 0.44361 \\
40.584 & 0.22229 & 200 & 0.44458 \\
58.758 & 0.15713 & 220 & 0.44443 \\
70.115 & 0.13421 & 311 & 0.44512 \\
73.868 & 0.12829 & 222 & 0.44441 \\
\end{tabular}

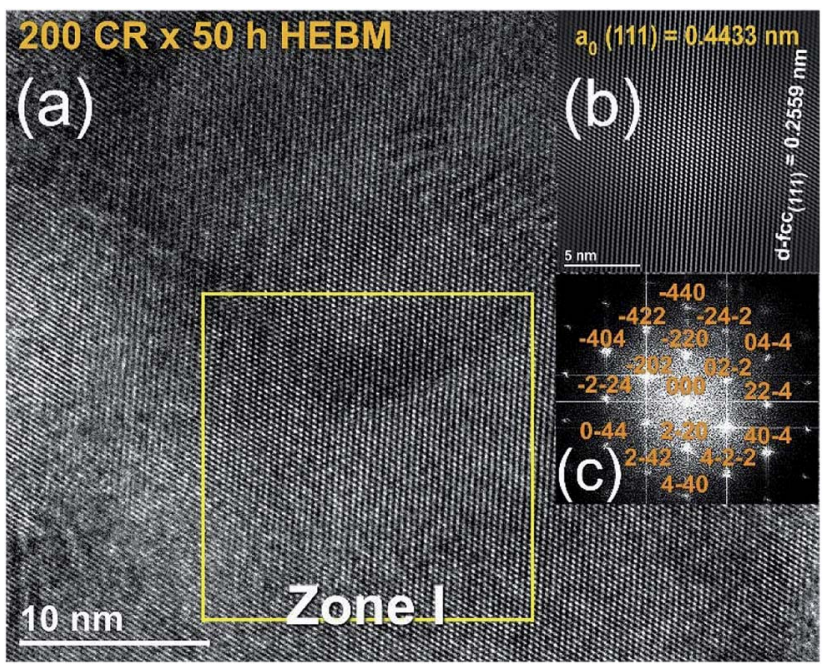

Fig. 4 (a) FE-HRTEM image, (b) filtered atomic resolution image of Zone I, and (c) FFT image of $\mathrm{MgH}_{2}$ powders obtained after $25 \mathrm{~h}$ of RBM, consequently CRed for 200 passes and finally HEBMed for $50 \mathrm{~h}$.

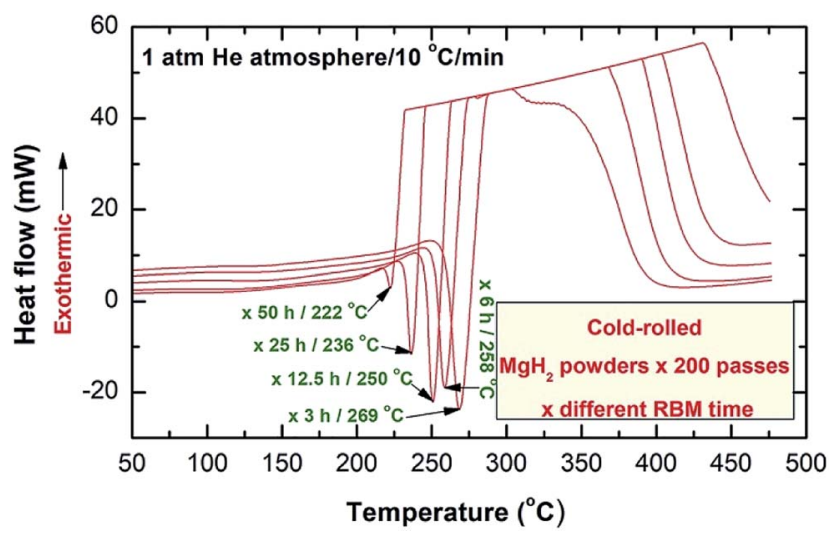

Fig. 5 DSC thermograms of $\mathrm{MgH}_{2}$ powders obtained after $25 \mathrm{~h}$ of RBM, consequently CRed for 200 passes and final HEBMed for different milling times ( $6 \mathrm{~h}$ to $50 \mathrm{~h}$ ). The values related to the peak temperatures for each milling time is elucidated in each curve.

CRing passes was attributed to destabilization of $\mathrm{MgH}_{2}$, yielded from introducing severe plastic deformation to the powders.

The XRD pattern for $\mathrm{MgH}_{2}$ powders obtained after $200 \mathrm{CRing}$ passes and then heated in DSC up to $500{ }^{\circ} \mathrm{C}$ showed the presence of a single hcp-Mg phase (Fig. S3†). The as-HEBMed of the powders CRed for 200 passes revealed single endothermic events related to the decomposition reaction (Fig. 5).
Obviously, the peak temperature of the samples obtained after different milling times shifted monotonically to the low temperature side with increasing the HEBMing time (Fig. 5). After $50 \mathrm{~h}$ of milling (single metastable fcc- $\mathrm{MgH}_{2}$ phase), the decomposition temperature was reordered to be $222{ }^{\circ} \mathrm{C}$ (Fig. 5). This temperature was far below the corresponding decomposition temperature $\left(361{ }^{\circ} \mathrm{C}\right.$, Fig. S3 $\dagger$ ) corresponding to as-CRed powders $\left(\gamma-+\beta-\mathrm{MgH}_{2}\right.$ phases $)$ obtained after 200 passes (Fig. S3†).

The powders obtained after $50 \mathrm{~h}$ of HEBM was annealed in the DSC at $220{ }^{\circ} \mathrm{C}$ (just beyond decomposition onset temperature) and at $375{ }^{\circ} \mathrm{C}$ (well above the onset decomposition temperature) for $7 \mathrm{~min}$. XRD pattern of the first sample annealed at $220{ }^{\circ} \mathrm{C}$ indicated metastable fcc- $\mathrm{MgH}_{2}$-to-stable $\beta$ $\mathrm{MgH}_{2}$ phase transformation, as implied by disappearance of fcc-Bragg peaks and the presence of pronounced sharp Bragg lines corresponding to $\beta-\mathrm{MgH}_{2}$ coexisted with small volume fraction of $\gamma-\mathrm{MgH}_{2}$ (Fig. 6a).

FE-HRTEM (Fig. 7a) and NBD (Fig. 7b) analysis of the annealed sample at $220{ }^{\circ} \mathrm{C}$ confirmed the presence of $\gamma$ - and $\beta$ $\mathrm{MgH}_{2}$ phases and a complete disappearance of metastable fcc$\mathrm{MgH}_{2}$, as displayed in Fig. 7a and b, respectively. In contrast, $\mathrm{XRD}$ pattern of the sample annealed at $375^{\circ} \mathrm{C}$ showed the Bragg peaks of hcp-Mg coexisted with small volume fraction of undecomposed $\beta-\mathrm{MgH}_{2}$ crystals (Fig. 6b). It can be concluded from the structural and thermal analysis that $\gamma$ - and $\beta-\mathrm{MgH}_{2}$ phases tended to transform to a new metastable phase upon

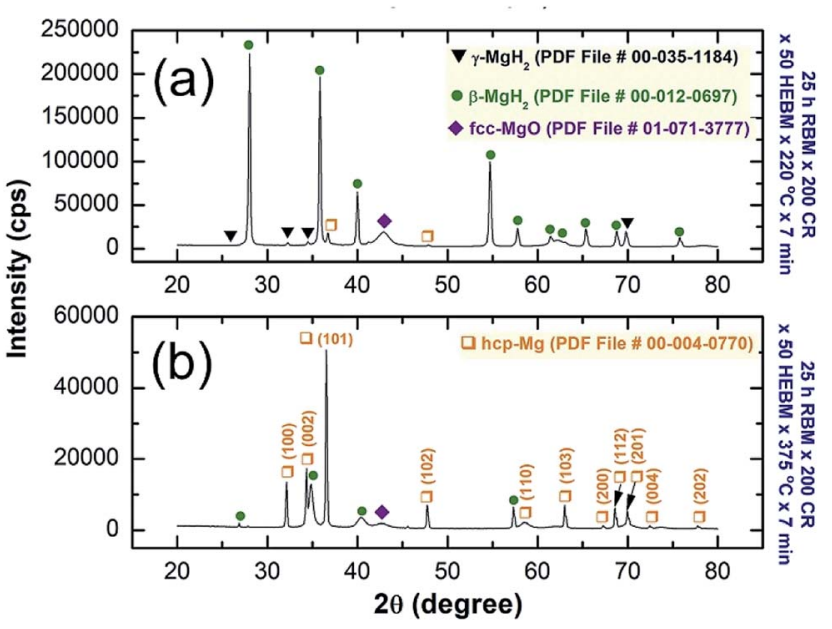

Fig. 6 XRD patterns of the samples obtained after $50 \mathrm{~h}$ and then annealed in the DSC for $7 \mathrm{~min}$ at (a) $220^{\circ} \mathrm{C}$, and (b) $375^{\circ} \mathrm{C}$ for $7 \mathrm{~min}$. 


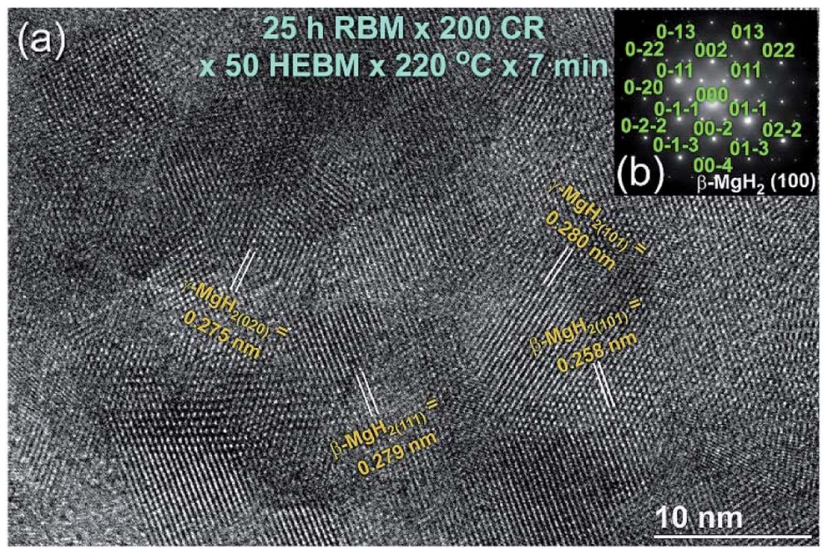

Fig. 7 (a) FE-HRTEM, and (b) NBDP of the sample milled for $50 \mathrm{~h}$ and then annealed in the DSC at $220^{\circ} \mathrm{C}$ for $7 \mathrm{~min}$.

CRing for 200 passes followed by HEBMing for $50 \mathrm{~h}$. The obtained metastable fcc- $\mathrm{MgH}_{2}$ phase transformed into more stable phases of $\gamma$-and $\beta-\mathrm{MgH}_{2}$ phases when annealed at $220{ }^{\circ} \mathrm{C}$ for $7 \mathrm{~min}$. A complete phase transformation to hcp-Mg was attained upon annealing fcc- $\mathrm{MgH}_{2}$ at $375{ }^{\circ} \mathrm{C}$.

Further experiments were conducted to examine the stability of fcc- $\mathrm{MgH}_{2}$ phase against the mechanical deformation generated by HEBMing. The powders obtained after $50 \mathrm{~h}$ were continuously milled for $100 \mathrm{~h}, 150 \mathrm{~h}$, and $200 \mathrm{~h}$. The XRD pattern of the milled powders for $100 \mathrm{~h}$ indicated the disappearance of Bragg peaks related fcc- $\mathrm{MgH}_{2}$ phase, which were replaced by diffracted lines related to $\gamma$ - and $\beta-\mathrm{MgH}_{2}$ phases as shown in Fig. 8a. This implies the disability of fcc- $\mathrm{MgH}_{2}$ phase to withstand against the shear and impact forces generated by the milling media. Surprisingly, increasing the HEBMing to $150 \mathrm{~h}$ led to clear $\gamma^{-}, \beta-\mathrm{MgH}_{2}$ to fcc- $\mathrm{MgH}_{2}$ (less stable phase) phase transformation (Fig. 8b). This is indicated by the presence of Bragg peaks related to fcc- $\mathrm{MgH}_{2}$ phase and the disappearance of the diffracted lines corresponding to the $\mathrm{MgH}_{2}$ phases, as displayed in Fig. 8 b.

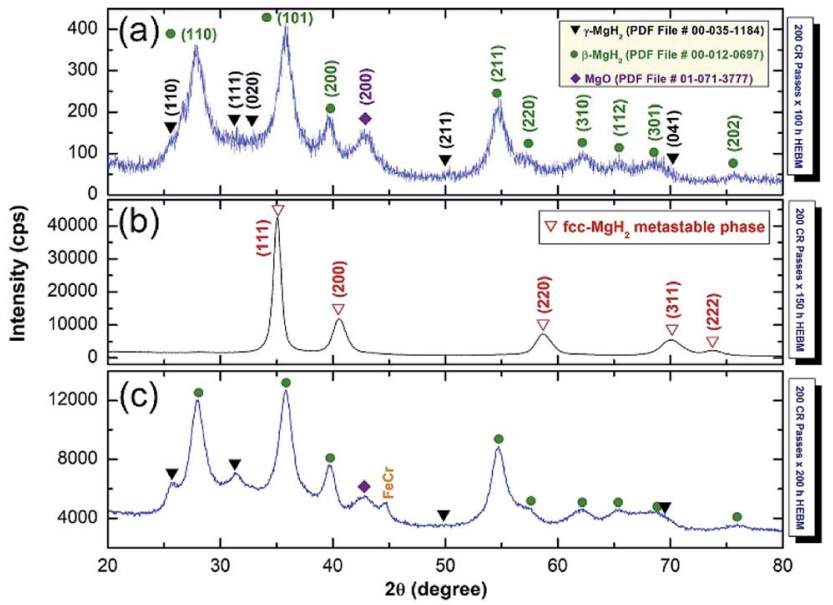

Fig. 8 XRD patterns of as-CRed $\mathrm{MgH}_{2}$ powders for 200 passes and then HEBMed for (a) 100 h, (b) 150 h, and (c) $200 \mathrm{~h}$.

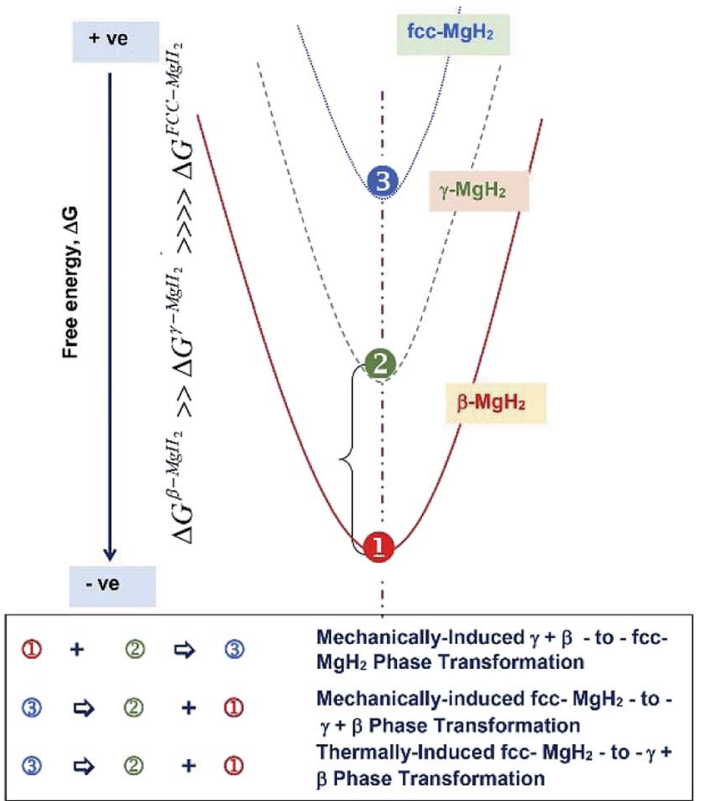

Fig. 9 Schematic presentation of free energy changes conducted upon $\mathrm{HEBMing} \mathrm{CRed} \mathrm{MgH}_{2}$ powders for long term of milling.

Fig. 9 presents a schematic illustration of free energy changes of $\beta$ - $\gamma$-fcc $\mathrm{MgH}_{2}$ phases upon increasing HEBM time. Based on the results motivated of the present study, mechanically-induced fcc- $\mathrm{MgH}_{2}$ to $\gamma$ - and $\beta-\mathrm{MgH}_{2}$ phase transformation (point 3-to-points $2+3$ ) was achieved upon increasing the milling time to $100 \mathrm{~h}$. Introducing severe lattice imperfections to the fcc-phase is proposed to be responsible to insist this metastable phase to gain free energy and hence transformed into a more stable phase, as illustrated in Fig. 9. This phase transformation can be taken place upon annealing the powders via thermally induced phase transformation, as indexed by point 3-to-points $2+1$ (Fig. 9).

The obtained $\gamma$-and $\beta-\mathrm{MgH}_{2}$ composite phases were subjected plastic deformation and defects, leading to lose free energy and transformed to the same metastable fcc- $\mathrm{MgH}_{2}$ phase with further milling time ( $150 \mathrm{~h}$ ), as denoted by points $1+2$ to point 3 (Fig. 9). Further increasing the milling time $(200 \mathrm{~h})$ led fcc- $\mathrm{MgH}_{2}$ to gain energy and failed into more stable phases of $\gamma$ - and $\beta-\mathrm{MgH}_{2}$.

Since high-energy ball milling process introduces intensive vacancies, lattice defects, grain boundaries and surfaces, the ball-milled powders can store a large amount of mechanicalstrain energy. ${ }^{33,34}$ Introducing such defects to the crystalline lattice destroys the periodical structure of the stable tetragonal$\mathrm{MgH}_{2}$ phase, leading to the formation of a less stable phase (fcc$\mathrm{MgH}_{2}$ ). Moreover, the present result suggests that the formation enthalpy of the metastable fcc- $\mathrm{MgH}_{2}$ phase is comparable to the $\gamma$ - and $\beta-\mathrm{MgH}_{2}$ phases and the energy barrier between these three phases is probably rather low to allow such cyclic-phase transformations. We should emphases that all the results obtained from XRD analysis were used to determine the weight percentage of each phase, using the approaches described by Guan et al., ${ }^{35}$ Ma et al., ${ }^{36}$ Yu et al., ${ }^{37}$ and Cheng et al. ${ }^{38}$ 
Fig. 10 displays the dehydrogenation kinetics behaviors of the CRed powder obtained after 200 passes and then HEBMed for $50 \mathrm{~h}$ (fcc- $\mathrm{MgH}_{2}$ phase). The measurements were conducted in the temperature range of $175{ }^{\circ} \mathrm{C}$ to $275{ }^{\circ} \mathrm{C}$ under $200 \mathrm{mbar}$.

In order to maintain the crystal structure of the powders (fcc$\mathrm{MgH}_{2}$ phase) obtained after this stage of milling, the desorption kinetics measurements measured without activation for 5 individual samples (Fig. 10a). All samples were successfully desorbed their hydrogen storage with different time scale. Generally, the fcc-MgH $\mathrm{H}_{2}$ powders showed advanced dehydrogenation characteristics over $\gamma$ - and $\beta-\mathrm{MgH}_{2}$ phases. At $175{ }^{\circ} \mathrm{C}$, the sample desorbed $\sim 4$ wt $\% \mathrm{H}_{2}$ within $40 \mathrm{~min}$ (Fig. 10a). However, the powders desorbed about $6.5 \mathrm{wt} \% \mathrm{H}_{2}$ within $22 \mathrm{~min}$ at $200{ }^{\circ} \mathrm{C}$ (Fig. 6a). Increasing the applied temperature to $225{ }^{\circ} \mathrm{C}$ and $250{ }^{\circ} \mathrm{C}$, improved the dehydrogenation kinetics of fcc- $\mathrm{MgH}_{2}$, indicated by the short time required to desorb $6.6 \mathrm{wt} \% \mathrm{H}_{2}$ in $17 \mathrm{~min}$ and $10 \mathrm{~min}$, respectively (Fig. 10a).

Outstanding desorption kinetics was conducted at $275{ }^{\circ} \mathrm{C}$, when the sample desorbed $6.6 \mathrm{wt} \% \mathrm{H}_{2}$ within $7 \mathrm{~min}$, as elucidated in Fig. 10a. We should emphases that the XRD patterns for the examined samples at temperature range laid between $175{ }^{\circ} \mathrm{C}$ to $225{ }^{\circ} \mathrm{C}$ revealed presence of Bragg peaks corresponding to $\gamma$ - and $\beta-\mathrm{MgH}_{2}$ phases. However, the XRD pattern for those samples examined at higher temperatures $\left(250{ }^{\circ} \mathrm{C}\right.$ and $275{ }^{\circ} \mathrm{C}$ ) revealed diffracted lines of hcp-Mg phase.
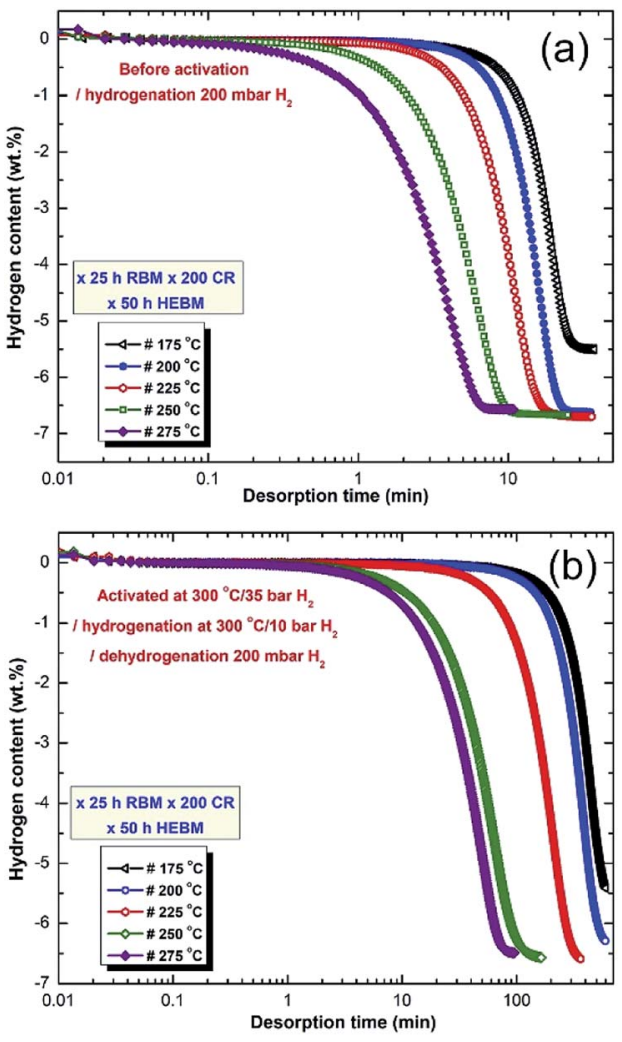

Fig. 10 Dehydrogenation kinetics measured for 10 individual samples of $\mathrm{MgH}_{2}$ powders obtained after $25 \mathrm{~h}$ of RBM, consequently CRed for 200 passes and then HEBMed for $50 \mathrm{~h}$. The measurements were conducted under $200 \mathrm{mbar}_{2}$ (a) without powders activation, and (b) after activated the powders at $300{ }^{\circ} \mathrm{C}$ under 10 bar $\mathrm{H}_{2}$.
Fig. 10b displays the dehydrogenation kinetics conducted for the same samples shown in 10a, however, they were activated firstly at $300{ }^{\circ} \mathrm{C}$ (far above the transformation temperature of fcc- $\mathrm{MgH}_{2}$ to $\gamma$ - and $\beta-\mathrm{MgH}_{2}$ phases) under $25 \mathrm{bar}_{2}$. Based on this activation step condition, all the samples lost their fccstructure and completely transformed into $\gamma$ - and $\beta-\mathrm{MgH}_{2}$ phases. This led to a significant deduction of dehydrogenation kinetics that become very slow when compared with the same samples shown in Fig. 10a. For example, the sample examined at $175{ }^{\circ} \mathrm{C}$ required more than $650 \mathrm{~min}$ to desorb less than $5.5 \mathrm{wt} \% \mathrm{H}_{2}$ (Fig. 10b). The two samples examined at $200{ }^{\circ} \mathrm{C}$ and $225{ }^{\circ} \mathrm{C}$ desorbed about 6.4 and $6.6 \mathrm{wt} \% \mathrm{H}_{2}$ within 600 and $390 \mathrm{~min}$, respectively (Fig. 10b). Comparing the necessary desorption time (100 min) for the sample examined at $275^{\circ} \mathrm{C}$ to release $6.6 \mathrm{wt} \% \mathrm{H}_{2}$ (Fig. 10b) with that time required ( $7 \mathrm{~min}$ ) for fcc- $\mathrm{MgH}_{2}$ sample (Fig. 10a) to desorb same hydrogen amount at the same temperature, we can realize that the kinetics desorption of fcc- $\mathrm{MgH}_{2}$ phase is 14 time faster than $\gamma$ - and $\beta-\mathrm{MgH}_{2}$ phases.

\section{Conclusions}

In summary, we have successfully developed a new metastable phase of fcc- $\mathrm{MgH}_{2}(F m \overline{3} m(225))$, which its lattice parameter $\left(a_{\mathrm{o}}\right)$ was calculated and found to be $0.4436 \mathrm{~nm}$. This discovered phase was obtained upon cold rolling of reacted ball milled $\mathrm{MgH}_{2}$ powders for 200 passes and consequently high energy ball milled for $50 \mathrm{~h}$. The results have shown outstanding desorption kinetics of this new phase, indexed by its capability to desorb 4-6.6 wt\% $\mathrm{H}_{2}$ at relatively low temperature $\left(175^{\circ} \mathrm{C}\right.$ to $250{ }^{\circ} \mathrm{C}$ ) in short time. At $275{ }^{\circ} \mathrm{C}$, metastable fcc- $\mathrm{MgH}_{2}$ completely discharged $6.6 \mathrm{wt} \% \mathrm{H}_{2}$ within $7 \mathrm{~min}$. This metastable phase transformed completely into $\gamma$ - and $\beta-\mathrm{MgH}_{2}$ upon annealing at $220{ }^{\circ} \mathrm{C}$ for $7 \mathrm{~min}$. Moreover, the present study confirms that mechanically induced fcc- $\mathrm{MgH}_{2}$ to $\gamma$ - and $\beta-\mathrm{MgH}_{2}$ phase transformation can be cyclically achieved upon increasing the high-energy ball milling time.

\section{Conflicts of interest}

There are no conflicts to declare.

\section{Acknowledgements}

Appreciation is extended to the Kuwait Foundation for the Advancement of Sciences (KFAS) for the partial financial support of this study related to the Project EA061C under a contract number: P315-35EC-01. The financial support received by the Kuwait Government through the Kuwait Institute for Scientific Research for purchasing the equipment used in the present work, using the budget dedicated for the project (P-KISR-06-04) led by the first author of Establishing Nanotechnology Center in KISR is highly appreciated.

\section{Notes and references}

1 M. Jefferson, Renewable Energy, 2006, 31, 571-582. 
2 T. Yamada, J. Yin and K. Tanaka, Mater. Trans., 2001, 42, 2415-2421.

3 I. P. Jain, C. Lal and A. Jain, Int. J. Hydrogen Energy, 2010, 35, 1121-1140.

4 L. Schlapbach and A. Züttel, Nature, 2001, 414, 353-358.

5 B. Sakintuna, F. Lamari-Darkrim and M. Hirscher, Int. J. Hydrogen Energy, 2007, 32, 1121-1140.

6 I. P. Jain, P. Jain and A. Jain, Int. J. Hydrogen Energy, 2010, 35, 5133-5144.

7 A. Calka, Appl. Phys. Lett., 1991, 59, 1568-1570.

8 M. Sherif El-Eskandarany, K. Sumiyama, K. Aoki and K. Suzuki, Mater. Sci. Forum, 1992, 88, 801-808.

9 G. Principi, F. Agresti, A. Maddalena and R. S. Lo, Int. J. Hydrogen Energy, 2009, 34, 2087-2091.

10 G. Liang, J. Huot, S. Boily, A. Van Neste and R. Schulz, J. Alloys Compd., 1999, 292, 247-252.

11 N. A. Ali, et al., RSC Adv., 2018, 8, 15667-15674.

12 A. Bhatnagar, et al., J. Mater. Chem. A, 2016, 4, 14761-14772.

13 Y. Wang, et al., J. Mater. Chem. A, 2014, 2, 16285-16291.

14 M. Sherif El-Eskandarany, Sci. Rep., 2016, 6, 26936, DOI: 10.1038/srep26936.

15 M. Sherif El-Eskandarany, et al., Mater. Chem. Phys., 2018, 203, 17-26.

16 H. Liu, X. Wang, Y. Liu, Z. Dong, G. Cao, S. Li and M. Yan, J. Mater. Chem. A, 2013, 1, 12527-12535.

17 J. Huot and J. Dufour, J. Alloys Compd., 2007, 446-447, 147151.

18 M. S. El-Eskandarany, H. Al-Matrouk, E. Shaban and A. AlDuweesh, Int. J. Hydrogen Energy, 2015, 40, 10139-10149.

19 J. Chen, H. Fu, Y. Xiong, J. Xu, J. Zheng and X. Li, Nano Energy, 2014, 10, 337-343.

20 M. S. El-Eskandarany, H. Al-Matrouk, E. Shaban and A. AlDuweesh, Energy, 2015, 91, 274-282.
21 G. Liu, et al., Nanoscale, 2013, 5, 1074-1081.

22 K. Edalati, et al., Scr. Mater., 2018, 157, 54-57.

23 C. Shen and K.-F. Aguey-Zinsou, J. Mater. Chem. A, 2017, 5, 8644-8652.

24 X. Xiao, Z. Liu, S. Saremi-Yarahmadi and D. H. Gregory, Phys. Chem. Chem. Phys., 2016, 18, 10492-10498.

25 F. Cuevas, D. Korablov and M. Latroche, Phys. Chem. Chem. Phys., 2012, 14, 1200-1211.

26 Z. Wang, et al., J. Mater. Chem. A, 2018, 6, 5652-5660.

27 R. Z. Valiev, R. K. Islamgaliev and I. V. Alexandrov, Prog. Mater. Sci., 2000, 45, 103-189.

28 M. Sherif El-Eskandarany, E. Shaban and B. Al-Halaili, Int. J. Hydrogen Energy, 2014, 39, 12727-12740.

29 S. Amira and J. Huot, J. Alloys Compd., 2012, 520, 287-294.

30 A. M. Jorge Jr, et al., Int. J. Hydrogen Energy, 2014, 39, 38103821.

31 Y. Mine, T. Tsumagari and Z. Horita, Scr. Mater., 2010, 63, 552-555.

32 P. Vajeeston, P. Ravindran, A. Kjekshus and H. Fjellvåg, Phys. Rev. Lett., 2002, 89, 175506-175509.

33 M. Sherif El-Eskandarany, K. Aoki, K. Sumiyama and K. Suzuki, Acta Mater., 2002, 50, 1113-1123.

34 M. Sherif El-Eskandarany and A. Inoue, Phys. Rev. B, 2007, 75, 224109.

35 S. Guan, X. Fu, Y. Zhang and Z. Peng, Chem. Sci., 2018, 9, 1574-1585.

36 X. Ma, Q. Xiang, Y. Liao, T. Wen and H. Zhang, Appl. Surf. Sci., 2018, 457, 846-855.

37 J. Yu, W. Wang, B. Cheng and B.-L. Su, J. Phys. Chem. C, 2009, 113, 6743-6750.

38 L. Cheng, Q. Xiang, Y. Liao and H. Zhang, Energy Environ. Sci., 2018, 11, 1362-1391. 